\title{
Stable Gradient Nanoflow LC-MS
}

\author{
Bradley B. Schneider, Xu Guo, Lorne M. Fell, and Thomas R. Covey \\ MDS SCIEX, Concord, Ontario, Canada
}

\begin{abstract}
This paper demonstrates improved nanoflow LC-MS performance on a QqTOF instrument with the incorporation of a heated nanoflow interface (particle discriminator) and a nebulizer assisted sprayer. It is shown that the nebulizer broadens the usable range of electrospray potentials, simplifying the tuning procedure, particularly for negative mode nanoflow gradients. The improved desolvation capability with the particle discriminator results in signal/noise improvements of approximately $3.5 \times$ for negative ion mode samples prepared in predominantly acidified water as well as increased ion current stability. For nanoLC applications, the combined desolvation capabilities of a counter-current gas and heated laminar flow chamber provide reduced background, increased signal stability, reduced background drift, and improved protein sequence coverage when compared with data generated with only a counter-current gas for desolvation. This system is capable of subfemtomole nanoflow LC-MS sensitivity in both positive and negative ion mode across the solvent gradient. (J Am Soc Mass Spectrom 2005, 16, 1545-1551) (C) 2005 American Society for Mass Spectrometry
\end{abstract}

$\mathrm{T}$ he interface between liquid chromatography (LC) and electrospray ionization-mass spectrometry (ESI-MS) has evolved substantially since its initial implementation in the 1980s [1]. Traditional LC systems operated at solvent flow rates that were orders of magnitude higher (hundreds of $\mu \mathrm{L} / \mathrm{min}$ to $\mathrm{mL} / \mathrm{min}$ ) than those used for mass spectrometry (tens of $\mu \mathrm{L} /$ $\mathrm{min})$, resulting in the need for solvent flow splitters [2]. Some of the subsequent improvements were focused on the use of nebulizer gases [3] and heating [4,5] for stabilization of the electrospray process to accommodate higher LC solvent flows.

An alternate approach involves modification of the LC system to accommodate separations within the nanoflow regime [6, 7]. Nanoflow LC-MS offers benefits in terms of sensitivity, solvent consumption, and sample consumption when compared with higher flow rate LC-MS, however, it can be much more difficult to operate. Nanoflow sprayers are typically fabricated from tapered fused silica capillary resulting in the need for some type of surface coating $[8,9]$, inserted electrode [10, 11], conductive union [6,12,13], or dialysis membrane [14] for application of the electrospray potential. Alternatively, sprayers can be fabricated from conductive materials, such as stainless steel, [15], however, tapered stainless steel sprayers are much more difficult to fabricate than fused silica sprayers. An additional benefit associated with fused silica sprayers is that the analytical column may be packed directly into the tapered sprayer, eliminating any post-column dead volume [16, 17].

Published online July 18, 2005

Address reprint requests to Dr. B. B. Schneider, MDS SCIEX, 71 Four Valley Drive, Concord, ON L4K 4V8, Canada. E-mail: bradley.schneider@sciex.com
A necessary but understated requirement for gradient elution in nanoLC-MS is an electrospray system that is capable of stable operation over a wide range of solvent compositions, particularly for samples containing both hydrophilic and hydrophobic components. Typical nanoflow electrospray systems display good stability for samples consisting of 20 to $100 \%$ organic solvent. However, stability can be an issue when running predominantly aqueous solvents because of the high surface tension of water [18] and the onset of corona discharge [19]. As a result, many of the nanoLC-MS systems described in the literature limit the gradient to avoid solvent conditions comprised of greater than approximately $90 \%$ water $[15,20,21]$. An alternate approach to solve this problem involves an automated control system that monitors the visual image of the spray and adjusts the electrospray potential over the course of a gradient to help stabilize the electrospray process [22].

Negative ion mode presents an even bigger problem for stable gradient nanoLC-MS. In many cases with acidified aqueous solvent, the onset potential for stable electrospray is higher than the onset potential for corona discharge. Under these conditions, it is not possible to generate a stable electrospray regardless of the sprayer potential. As a result, examples of LC-MS in the negative ion mode predominantly involve higher flow rates $[23,24]$ and more restricted solvent compositions [25].

Recently, we described a new interface and nanoflow source configuration [26] that provided substantial improvements in performance for infusion of aqueous solvents in the positive ion mode. This system incorporated a heated nanoflow interface (particle discriminator interface) and a nebulizer assisted nanoflow sprayer 
(MicroIonSpray ${ }^{\circledR}$ assembly). A modified version of this interface has also been shown to generate stable nanoLC-MS data in the positive ion mode for solvents ranging from 95 to $10 \%$ acidified water without nebu-

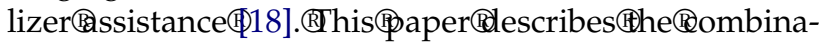
tion of the particle discriminator interface and a new MicroIonSpray prototype assembly to stabilize the performance for gradient elution nanoLC-MS in both the positive and negative ion mode. Performance comparisons are made to the standard interface arrangement (curtain plate before the orifice) for nanoLC-MS and negative ion mode infusion of samples prepared in acidified water. These results show that nebulizer assistance is a critical aspect for stabilizing the electrospray process and broadening the usable range of electrospray potentials before the onset of corona discharge when operating in the negative ion mode. With this configuration, it is possible to achieve stable electrospray in either polarity for samples prepared in predominantly acidified water. It is also possible to conduct stable nanoLC-MS experiments with no need to adjust the electrospray potential across the solvent gradient because the nebulizer gas broadens the range of usable electrospray potentials.

\section{Experimental}

For negative ion mode infusion experiments, samples of taurocholic acid (Sigma Chemical Co., St. Louis, MO) were prepared at concentrations of 100 or $200 \mathrm{pg} / \mu \mathrm{L}$ in solvents ranging from 95/5 water/methanol (Fisher Scientific, Nepean, ON, Canada) with $0.1 \%$ formic acid (Aldrich, Milwaukee, WI) to 50/50 water/methanol with $0.1 \%$ formic acid. Glufibrinopeptide b (Sigma Chemical Co., St. Louis, MO) was prepared at various concentrations in $98 / 2$ water/acetonitrile with $0.1 \%$ formic acid. Bovine serum albumin (reduced and carboxymethylated BSA) and $\alpha$-casein were purchased from Sigma Chemical Co. Before digestion, protein samples were prepared at $5 \mathrm{mg} / \mathrm{mL}$ in $50 \mathrm{mM}$ ammonium bicarbonate (BDH Chemicals, Toronto, ON, Canada) buffer adjusted to $\mathrm{pH} 8.5$ with ammonium hydroxide (Fisher Scientific). Digestions were carried out with a ratio of 20:1 protein:trypsin. Proteins were digested for $4 \mathrm{~h}$ at $37^{\circ} \mathrm{C}$, and the digests were stored at $-20^{\circ} \mathrm{C}$ before use. Digests were reconstituted in $98 / 2$ water/ acetonitrile with $0.1 \%$ formic acid before the nanoLC-MS runs. $\beta$-Galactosidase digest was purchased from Michrome Bioresources Inc. (Auburn, CA). For infusion experiments, samples were infused at 500 $\mathrm{nL} / \mathrm{min}$ using a syringe pump from Harvard Apparatus (South Natick, MA).

NanoLC experiments were performed at flow rates of $300 \mathrm{~nL} / \mathrm{min}$ using an LC Packings Ultimate system (San Francisco, CA) with a FAMOS (San Francisco, CA) autosampler. A 75 micron column $\left(\mathrm{C}_{18}\right.$ packing, $5 \mu \mathrm{m}$ particle size, $15 \mathrm{~cm}$ length, Grace Vydac, Hesperia, CA) was coupled to a tapered fused silica sprayer tip (360 $\mu \mathrm{m}$ o.d. tapered to $15 \mu \mathrm{m}$ i.d.) from New Objective Inc.
(Woburn, MA). Initial conditions for the gradient nanoLC-MS experiments were approximately $98 \%$ acidified water for $5 \mathrm{~min}(0-5 \mathrm{~min})$, followed by a gradient run out to $60 \%$ acidified water over the course of approximately $30 \mathrm{~min}$ (5-35 $\mathrm{min})$. The column was subsequently rinsed with $20 \%$ acidified water for about 5 min before equilibration with $98 \%$ acidified water for $20 \mathrm{~min}$.

The sample transfer line, or nanoLC column was coupled to the sprayer tip using a prototype MicroIon-

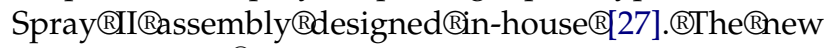
MicroIonSpray ${ }^{\circledR}$ prototype was specifically designed to provide better isolation of the nebulizer gas supply from the sample flow stream, facilitating the use of higher nebulizer gas settings. The sprayer tip was positioned within the MicroIonSpray assembly such that the nebulizer gas (compressed air, Praxair, Mississauga, ON, Canada) emanated from approximately 1 $\mathrm{mm}$ behind the tip. The i.d. of the gas tube within the adjustable nebulizer was bored out to $500 \mu \mathrm{m}$, leaving an annular space of 70 to $90 \mu \mathrm{m}$ around the fused silica capillary tip (360 $\mu \mathrm{m}$ o.d., $320 \mu \mathrm{m}$ with the polyimide coating burned off).

The mass spectrometer used for these studies was a QSTAR $^{\circledR} \mathrm{XL}^{\circledR}$ (Applied Biosystems/MDS SCIEX, Concord, ON, Canada) equipped with a prototype particle discriminator interface. The differences between the standard interface configuration and the particle discriminator interface have been discussed previously

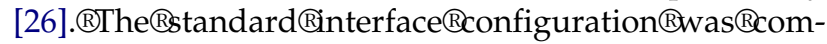
prised of a gas conductance limiting orifice plate (250 $\mu \mathrm{m}$ aperture) and a nanoflow curtain plate $(4 \mathrm{~mm}$ aperture) spaced approximately $1 \mathrm{~mm}$ in front of the orifice to direct a counter-current drying gas. For the particle discriminator interface a $1 \mathrm{~cm}$ long heated laminar flow chamber $(1 \mathrm{~mm}$ i.d.) was installed before the standard orifice. Removal or installation of the heated chamber did not require shutting down the vacuum pumps, as it was the orifice that provided the gas flow restriction into the system. A modified curtain plate ( $8 \mathrm{~mm}$ aperture) was installed $3 \mathrm{~mm}$ in front of the entrance to the heated chamber and directed a countercurrent flow of nitrogen gas (Praxair, Mississauga, ON) past the sprayer. Two ceramic heaters (Kyocera, Kyoto, Japan) were installed on the laminar flow chamber, and the temperature was controlled through Analyst ${ }^{\circledR} \mathrm{QS}^{\circledR}$ software version 1.1 (Applied Biosystems/MDS SCIEX). With this configuration, the optimum sprayer position was typically flush with or slightly inserted (approximately $1 \mathrm{~mm}$ ) into the curtain chamber.

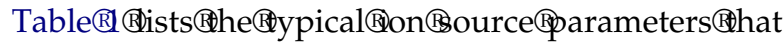
were used with the two interfaces unless otherwise stated. As a result of a predominance of cluster ions when running aqueous samples with the standard interface in the negative ion mode, a large spacing was necessary between the sprayer and the orifice to optimize the $\mathrm{S} / \mathrm{N}$. 
Table 1. Typical source tuning parameters with the standard and particle discriminator interfaces

\begin{tabular}{|c|c|c|c|c|}
\hline & \multicolumn{2}{|c|}{ Standard interface } & \multicolumn{2}{|c|}{ Particle discriminator } \\
\hline & Positive mode & $\begin{array}{l}\text { Negative } \\
\text { mode }\end{array}$ & Positive mode & $\begin{array}{l}\text { Negative } \\
\text { mode }\end{array}$ \\
\hline Electrospray potential (V) & 2400 & -1400 & 2100 & -1400 \\
\hline Curtain Plate potential (V) & 250 & -250 & 250 & -250 \\
\hline Laminar flow chamber potential (V) & $\mathrm{N} / \mathrm{A}$ & $\mathrm{N} / \mathrm{A}$ & 250 & -250 \\
\hline Laminar flow chamber temperature $\left({ }^{\circ} \mathrm{C}\right)$ & $\mathrm{N} / \mathrm{A}$ & $\mathrm{N} / \mathrm{A}$ & 100 & 190 \\
\hline Distance from sprayer to inlet $(\mathrm{mm})$ & 3 & 15 & 2 & 2 \\
\hline Curtain gas setting (L/min) & $\begin{array}{l}1.3 \text { (Analyst } \\
\text { setting }=25 \text { ) }\end{array}$ & $\begin{array}{l}1.3 \text { (Analyst } \\
\text { setting }=25)\end{array}$ & $\begin{array}{l}1.3 \text { (Analyst } \\
\text { setting }=25)\end{array}$ & $\begin{array}{l}1.3 \text { (Analyst } \\
\text { setting }=25 \text { ) }\end{array}$ \\
\hline Nebulizer setting (L/min) & $\begin{array}{l}0.65 \text { (Analyst } \\
\text { setting }=10 \text { ) }\end{array}$ & $\begin{array}{l}1.00 \text { (Analyst } \\
\text { setting = 18) }\end{array}$ & $\begin{array}{l}0.82 \text { (Analyst } \\
\text { setting }=14 \text { ) }\end{array}$ & $\begin{array}{l}1.32 \text { (Analyst } \\
\text { setting }=25 \text { ) }\end{array}$ \\
\hline
\end{tabular}

\section{Results and Discussion}

Initial optimization experiments were conducted to determine the effect of a nebulizer gas on the negative ion electrospray potential, ion count stability, and sensitivity. The results shown here are from the particle discriminator interface but similar trends for the relationship between gas flow and ESI potential were observed with the standard interface and the source parameters optimized for stability and $\mathrm{S} / \mathrm{N}$ for both

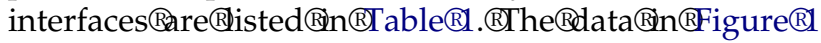
show the broad ESI potential optimum that can be achieved at higher gas flow settings, in particular with respect to solvent composition. In predominantly acid-

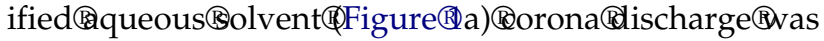
observed before the onset of stable electrospray at low gas flow. The spray process was disrupted by the discharge, resulting in destabilization of the signal and reduced sensitivity. Increasing the nebulizer gas flow created a stable spray process by pneumatic means and also served to suppress the onset of a visible discharge. At higher organic contents the effect was similar but

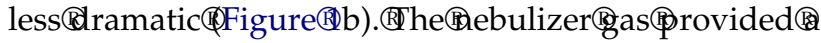
broader range of usable electrospray potentials and no substantial loss of signal compared to runs with gas flows sufficiently low as to afford no nebulization. Although not shown in this figure, the results with no gas were similar to those obtained at the lowest gas settings shown. Increasing the composition of organic solvent also served to suppress corona discharge attributable to a reduction in the conductivity of the electrosprayed[solutionథ19].

Valaskovic@t@1.\$22] बemonstrated(That 1 he@ptimum electrospray potential can vary significantly with solvent composition over the course of a gradient elution nanoLC-MS experiment in the absence of nebulizer

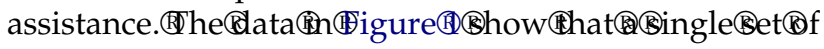
ion source conditions, initially established under high aqueous conditions, can be chosen to provide optimal operational parameters across a broad solvent composition range typical of gradient operation. In this instance, a nebulizer gas setting of $1.32 \mathrm{~L} / \mathrm{min}$ and an electrospray potential of $-1400 \mathrm{~V}$ would provide maximum stability giving absolute signal intensity within
$20 \%$ of maximum across the gradient. Although not shown, the source parameters for operation with higher organic content were very similar to the $50 / 50$ results. However, because of the differences in sprayers, it is important to determine the optimum sprayer potential any time a sprayer tip is changed to ensure that optimum performance will be achieved.

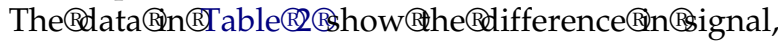
signal-to-noise, and stability typical of the two inter-
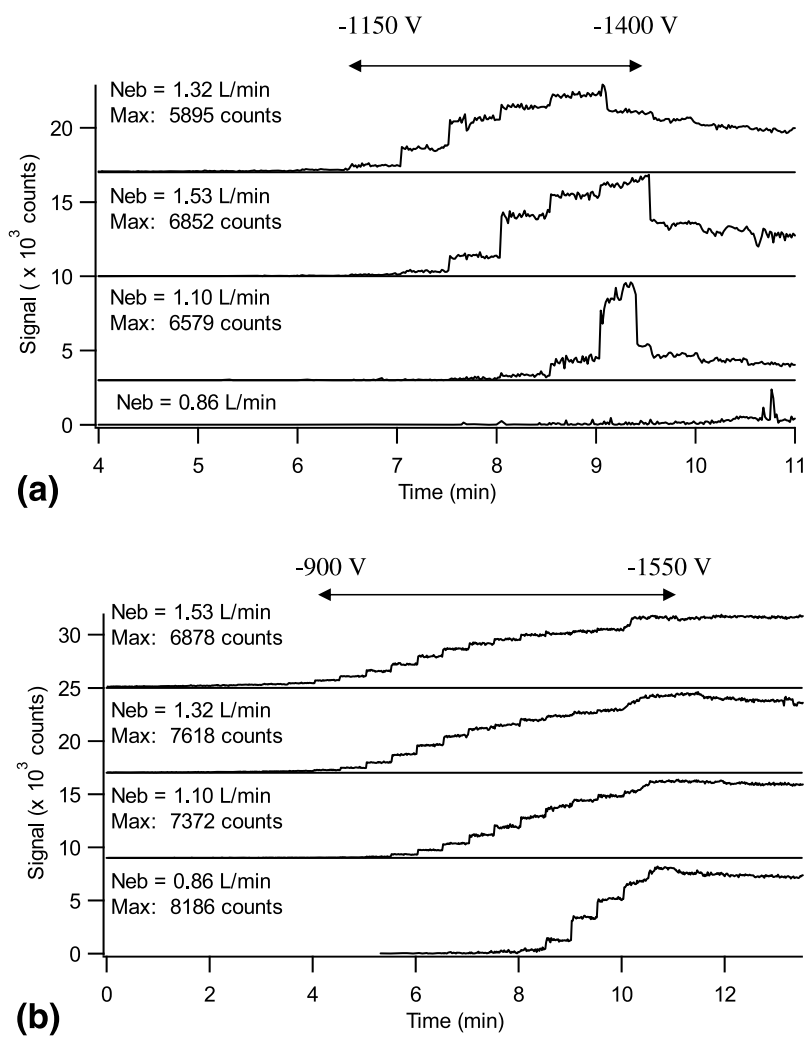

Figure 1. Extracted ion count (XIC) profiles for the $(\mathrm{M}-\mathrm{H})^{-}$ion from $100 \mathrm{pg} / \mu \mathrm{L}$ of taurocholic acid. The electrospray potential was stepped ( $50 \mathrm{~V}$ increments) during infusion at $500 \mathrm{~nL} / \mathrm{min}$. The ESI potential step was repeated with nebulizer gas flows ranging from 0.86 to $1.53 \mathrm{~L} / \mathrm{min}$. All data were acquired using the particle discriminator interface. (a) The solvent consisted of $95 / 5$ water/ methanol with $0.1 \%$ formic acid. (b) The solvent consisted of $50 / 50$ water/methanol with $0.1 \%$ formic acid. 
Table 2. Comparison of the peak height, ion count stability, and $\mathrm{S} / \mathrm{N}$ ratio for samples of taurocholic acid with the standard and particle discriminator interfaces. The $\mathrm{S} / \mathrm{N}$ was calculated based upon $3 \sigma$ where $\sigma$ was the standard deviation of the background from a $10 \mathrm{amu}$ window beside the molecular ion. The solution was $200 \mathrm{pg} / \mu \mathrm{L}$ taurocholic acid prepared in $95 / 5$ water/methanol with $0.1 \%$ formic acid infused at $500 \mathrm{~nL} / \mathrm{min}$ for 30 minutes

\begin{tabular}{|c|c|c|c|c|c|c|}
\hline \multirow[b]{2}{*}{ Run } & \multicolumn{3}{|c|}{ Standard Interface } & \multicolumn{3}{|c|}{ Particle Discriminator } \\
\hline & $\begin{array}{l}\text { Peak height } \\
\text { (counts) }\end{array}$ & $\mathrm{S} / \mathrm{N}$ ratio & $\begin{array}{c}\text { RSD of XIC } \\
(\%)\end{array}$ & $\begin{array}{l}\text { Peak height } \\
\text { (counts) }\end{array}$ & $\mathrm{S} / \mathrm{N}$ ratio & $\begin{array}{c}\text { RSD of XIC } \\
(\%)\end{array}$ \\
\hline 1 & 418 & 142 & 2.92 & 1583 & 621 & 0.70 \\
\hline 2 & 428 & 153 & 2.79 & 1626 & 506 & 0.70 \\
\hline 3 & 440 & 159 & 3.30 & 1594 & 597 & 1.20 \\
\hline 4 & 463 & 166 & 3.45 & 1593 & 547 & 0.70 \\
\hline 5 & 465 & 166 & 2.55 & 1548 & 543 & 1.01 \\
\hline 6 & 559 & 227 & 2.84 & 1490 & 671 & 0.90 \\
\hline 7 & 567 & 236 & 1.76 & 1452 & 864 & 1.20 \\
\hline 8 & 531 & 229 & 2.91 & 1450 & 832 & 1.00 \\
\hline Average & 484 & 185 & 2.82 & 1542 & 648 & 0.93 \\
\hline
\end{tabular}

faces fully optimized for the sample introduction conditions described. The PDI provided, on the average, a $3.2 \times$ improvement in peak height, a $3.0 \times$ improvement in signal stability, and a $3.5 \times$ improvement in $\mathrm{S} / \mathrm{N}$ relative to the standard interface configuration. The reasons for the improved performance with the particle discriminator interface were improved sampling efficiency attributable to the proximity of the sprayer to the inlet and improved desolvation efficiency due to the addition of the heated laminar flow chamber. The standard counter-current gas flow provided insufficient desolvation capability when using high nebulizer gas flows. To compensate for this and to eliminate excessive chemical noise resulting from clusters, it was necessary to operate with the sprayer more than $1 \mathrm{~cm}$ outside of the standard curtain plate to achieve the highest $\mathrm{S} / \mathrm{N}$ ratio. For negative ion mode samples containing higher organic content, the sprayer optimized much closer to the standard curtain plate. This substantial difference in the optimal tuning parameters for negative ion mode (standard interface) with different solvent compositions caused nanoLC-MS performance to be compromised.

Figure@(8hows@irect@verlay@f injections of BSA digest using the standard interface and particle discriminator interface. The TIC background was approximately $2.5 \times$ higher with the standard interface. In addition, the TIC intensity drifted significantly with the standard interface depending upon the solvent composition. However, the improved desolvation capability of the particle discriminator interface resulted in a stable background, with minimal drift over the course of the gradient. There was a substantial improvement in the TIC $\mathrm{S} / \mathrm{N}$ ratios for peptide peaks. The improved stability with the heated interface was also apparent when comparing the initial and final TIC signals with the two configurations. Even though the initial and final solvent compositions were identical (98\% acidified water), the final TIC signal was substantially higher than the initial signal with the standard interface. This trend of increasing TIC back- ground may occur as a result of wetting of the unheated orifice plate over the course of the experiments.

The improvements in stability, sensitivity, and S/N provided by the PDI interface translated directly into

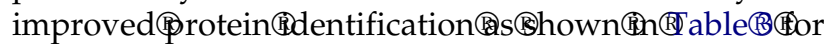
injections of various levels of BSA digest. These experiments involved information dependant acquisition (IDA) to conduct automated MS/MS for peaks detected with the TOF-MS scans. The benefits of the PDI interface were most apparent with injections of lower levels of digest, demonstrating sequence coverage improvements of 1.4 and $1.9 \times$ at the 10 and 1 fmol levels,
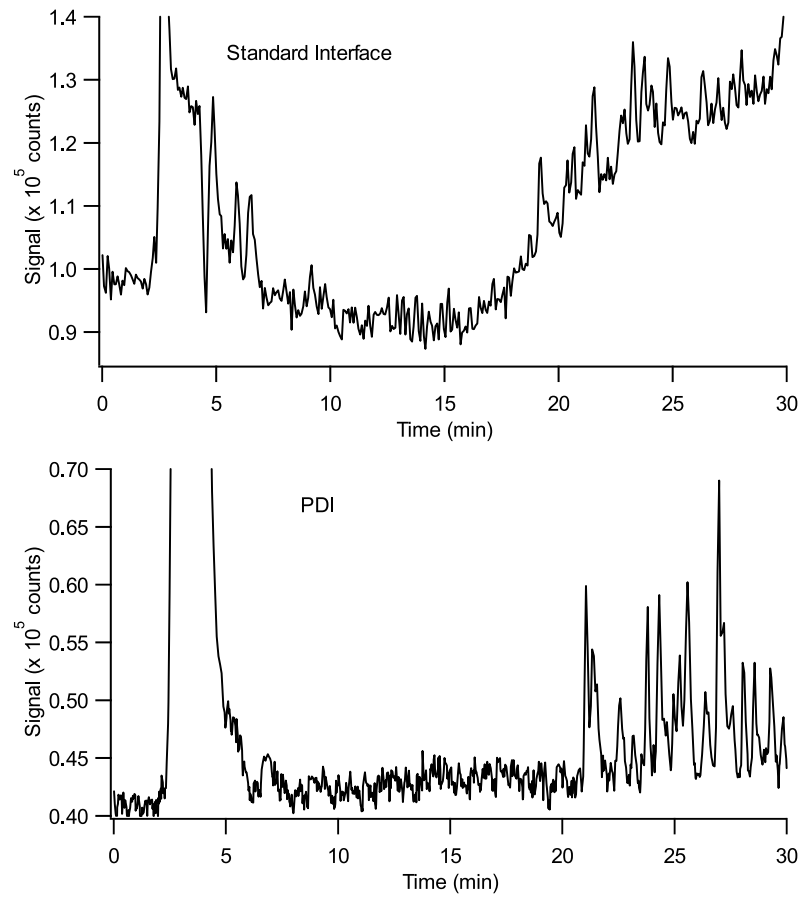

Figure 2. Comparison of total ion count (TIC) traces for $10 \mathrm{fmol}$ injections of BSA digest using the standard and the particle discriminator interfaces showing reduced background drift as well as improved $\mathrm{S} / \mathrm{N}$ with the heated interface. 
Table 3. MASCOT search results for positive ion mode nanoLC-MS runs with 8 replicate injections of various levels of BSA digests. MASCOT searches were conducted for singly and multiply charged parent ions allowing for 1 missed cleavage and carboxymethylation of the peptides from the tryptic digests. The TOF/MS and MS/MS tolerances were 0.1 and $0.1 \mathrm{Da}$, respectively

\begin{tabular}{cccccccc}
\hline & \multicolumn{3}{c}{ Heated nanoflow interface } & & \multicolumn{3}{c}{ Standard interface } \\
\cline { 2 - 4 } $\begin{array}{c}\text { Amount of } \\
\text { BSA loaded } \\
\text { on column }\end{array}$ & $\begin{array}{c}\text { Number of unique } \\
\text { peptides identified }\end{array}$ & $\begin{array}{c}\text { Sequence } \\
\text { coverage (\%) }\end{array}$ & $\begin{array}{c}\text { MASCOT } \\
\text { score }\end{array}$ & & $\begin{array}{c}\text { Number of unique } \\
\text { peptides identified }\end{array}$ & $\begin{array}{c}\text { Sequence } \\
\text { coverage (\%) }\end{array}$ & $\begin{array}{c}\text { MASCOT } \\
\text { score }\end{array}$ \\
\hline \hline $100 \mathrm{fmol}$ & $49 \pm 2$ & $70.9 \pm 1.3$ & $2594 \pm 86$ & & $44 \pm 4$ & $63.6 \pm 7.6$ & $2179 \pm 215$ \\
$10 \mathrm{fmol}$ & $39 \pm 1$ & $61.5 \pm 1.8$ & $1772 \pm 164$ & & $30 \pm 4$ & $45.5 \pm 7.7$ & $1175 \pm 144$ \\
$1 \mathrm{fmol}$ & $20 \pm 1$ & $35.0 \pm 1.7$ & $776 \pm 19$ & & $11 \pm 1$ & $18.8 \pm 2.3$ & $322 \pm 45$ \\
\hline
\end{tabular}

Table 4. XIC peak height and S/N data for the negative ion mode nanoLC-MS runs with injections of various amounts of glufibrinopeptide $\mathrm{b}$ on-column

\begin{tabular}{|c|c|c|c|c|c|c|}
\hline \multirow[b]{2}{*}{ Replicate } & \multicolumn{2}{|c|}{$100 \mathrm{fmol}$} & \multicolumn{2}{|c|}{$10 \mathrm{fmol}$} & \multicolumn{2}{|c|}{$1 \mathrm{fmol}$} \\
\hline & $\begin{array}{c}\text { XIC Peak } \\
\text { height (counts) }\end{array}$ & XIC S/N & $\begin{array}{c}\text { XIC peak } \\
\text { height (counts) }\end{array}$ & XIC S/N & $\begin{array}{c}\text { XIC peak } \\
\text { height (counts) }\end{array}$ & XIC S/N \\
\hline 1 & 5527 & 327.5 & 748 & 44.2 & 78 & 5.0 \\
\hline 2 & 6204 & 323.8 & 751 & 52.3 & 88 & 5.1 \\
\hline 3 & 6311 & 401.3 & 816 & 54.4 & 89 & 4.6 \\
\hline Average & 6014 & 350.9 & 772 & 50.3 & 85 & 4.9 \\
\hline RSD & $7.1 \%$ & $12.5 \%$ & $5.0 \%$ & $10.7 \%$ & $7.2 \%$ & $5.4 \%$ \\
\hline
\end{tabular}

respectively. Run to run variations (as measured by the $\%$ RSD) in the sequence coverage were approximately 14 and 3\% with the standard interface configuration and particle discriminator, respectively. The reproducibility of the MASCOT scores (\% RSD) was approximately 12 and 5\% for the standard interface and the heated interface, respectively. Therefore, the PDI gave improvements in both the sequence coverage and the run-run reproducibility relative to the standard interface@onfiguration. $\mathrm{Whe}$ (ata)

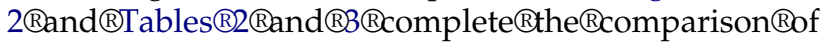
sensitivity for the standard interface configuration and the particle disciminator interface. There is no direct comparison of the performance with the two interfaces for negative ion mode nanoLC-MS because of difficulties with tuning the standard interface for stable gradient operation, as previously described. The rest of the data in this paper were generated using only the particle discriminator interface.

Table®®hows®he®eproducibility®f®he®ignal®nd $\mathrm{S} / \mathrm{N}$ for replicate injections of glufibrinopeptide $\mathrm{b}$ attainable with gradient elution in the negative ion mode. Initial tuning parameters were optimized for the aqueous portion of the gradient ( $98 \%$ acidified water) and used throughout the gradient. Statistical data is pre-

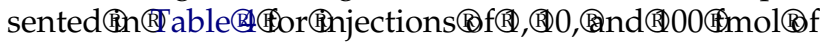
peptide. Chromatographic peak heights, retention times, and $\mathrm{S} / \mathrm{N}$ ratios were very reproducible with this configuration. The $\mathrm{S} / \mathrm{N}$ ratio was approximately 5 for replicate injections of 1 fmol of glufibrinopeptide $b$.

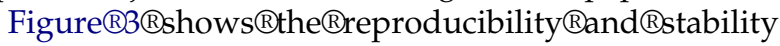
across the solvent gradient for replicate injections of 100 fmol BSA digest in the positive ion mode. The 5 TICs were qualitatively similar, displaying stable ion current throughout the gradient. The majority of the peptides eluted over the time period of approximately 15 to 35 min, however, a few of the more hydrophilic peptides eluted earlier. The retention times and intensities for the peaks were reproducible, with approximately 2 to $14 \%$ RSD from run to run. Similar data were generated for replicate measurements with samples of $\beta$-galactosidase digest as well (data not shown).

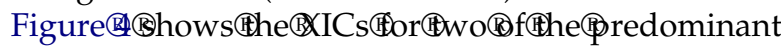
phosphopeptides $(\mathrm{m} / \mathrm{z} 974$ and 829) from a gradient elution nanoLC-MS run in the negative ion mode with $100 \mathrm{fmol}$ of $\alpha$-casein digest. The retention times for the two phosphopeptides were approximately 24 and 25.5 min for $m / z 829$ and 974, respectively. The baselines were stable regardless of solvent composition and the $\mathrm{S} / \mathrm{N}$ values suggest that the limits of detection for these phosphopeptides in this digest were in the low fmol range.

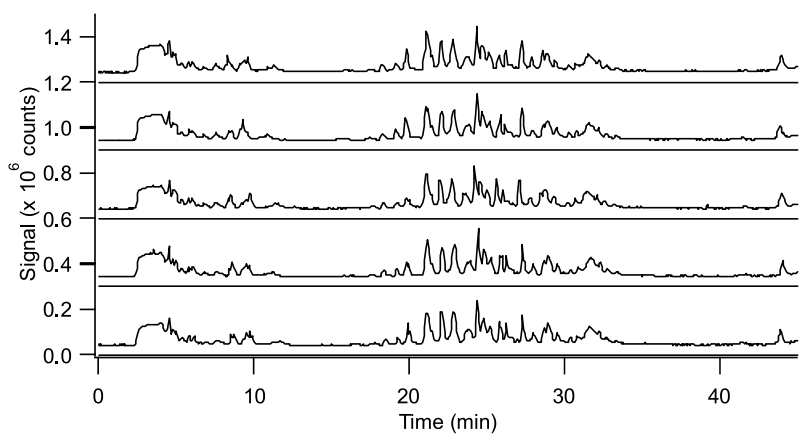

Figure 3. Positive mode gradient elution nanoLC-MS reproducibility for five replicate $100 \mathrm{fmol}$ injections of BSA digest using the particle discriminator interface. 


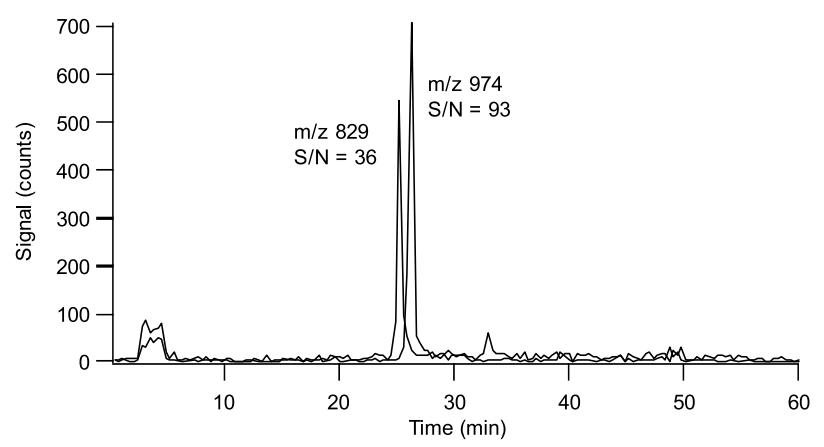

Figure 4. XIC for two doubly deprotonated phosphopeptides from a gradient elution nanoLC-MS experiment conducted in the negative ion mode using $100 \mathrm{fmol}$ of $\alpha$-casein digest. The calculated monoisotopic masses for the neutral peptides were 1659.79 (VPQLEIVPNpSAEER) and 1950.95 (YKVPQLEIVPNPSAEER). The $\mathrm{S} / \mathrm{N}$ ratios were 36 and 93 , respectively for the two phosphopeptides in this digest.

\section{Conclusions}

The results presented in this paper demonstrate that a QqTOF system incorporating a heated particle discriminator interface and a nebulizer assisted nanoflow source is capable of stable and robust gradient elution nanoflow LC-MS in both the positive and negative ion mode. There is no need for make-up buffers or limitation of the gradient conditions to prevent corona discharge or droplet accumulation under these conditions. The nebulizer gas simplifies source tuning by broadening the optimum range of electrospray potentials while providing negligible loss of system performance with changing solvent composition. The improved desolvation capability provided with the combination of heat and counter-current gas using the particle discriminator interface provides improved stability, robustness, and protein identification capability. This configuration enables unprecedented stability for nanoLC-MS in the negative ion mode, enabling the investigation of lower abundance samples in standard application areas such as protein digest, steroid, and lipid analysis.

\section{Acknowledgments}

The authors thank Deolinda Fernandes for preparing the samples used in these studies. This work was supported by the Natural Sciences and Engineering Research Council of Canada (NSERC) and Applied Biosystems/MDS SCIEX. This work was performed as part of Genome Prairie's Enabling Technologies Project.

\section{References}

1. Whitehouse, C. M.; Dreyer, R. N.; Yamashita, M.; Fenn, J. B. Electrospray Interface for Liquid Chromatographs and Mass Spectrometers. Anal. Chem. 1985, 57, 675-679.

2. Crescenzi, C.; Corcia, A. D.; Marchese, S.; Samperi, R. Determination of Acidic Pesticides in Water by a Benchtop Electrospray Liquid Chromatography Mass Spectrometer. Anal. Chem. 1995, 67, 1968-1975.

3. Bruins, A. P.; Covey, T. R.; Henion, J. D. Ion Spray Interface for Combined Liquid Chromatography/Atmospheric Pressure Ionization Mass Spectrometry. Anal. Chem. 1987, 59, 2642-2646.
4. Peng, S. X.; King, S. L.; Bornes, D. M.; Foltz, D. J.; Baker, T. R.; Natchus, M. G. Automated 96-Well SPE and LC-MS-MS for Determination of Protease Inhibitors in Plasma and Cartilage Tissues. Anal. Chem. 2000, 72, 1913-1917.

5. Volmer, D. A.; Brombacher, S.; Whitehead, B. Studies on Azaspiracid Biotoxins. I. Ultrafast High-Resolution Liquid Chromatography/Mass Spectrometry Separations using Monolithic Columns. Rapid Commun. Mass Spectrom. 2002, 16, 2298-2305.

6. Davis, M. T.; Stahl, D. C.; Hefta, S. A.; Lee, T. D. A. Microscale Electrospray Interface for On-Line Capillary Liquid Chromatography/Tandem Mass Spectrometry of Complex Peptide Mixtures. Anal. Chem. 1995, 67, 4549-4556.

7. Harris, C. M. Shrinking the LC Landscape. Anal. Chem. 2003, $75,64 \mathrm{~A}-69 \mathrm{~A}$.

8. Wahl, J. H.; Gale, D. C.; Smith, R. D. Sheathless Capillary Electrophoresis Electrospray Ionization Mass Spectrometry Using $10 \mathrm{mu}$ m/d Capillaries-Analyses of Tryptic Digests of Cytochrome c. J. Chromatogr. A. 1994, 659, 217-222.

9. Kriger, M. S.; Cook, K. D.; Ramsey, R. S. Durable Gold-Coated Fused Silica Capillaries for Use in Electrospray Mass Spectrometry. Anal. Chem. 1995, 67, 385-389.

10. Fang, L.; Zhang, R.; Williams, E. R.; Zare, R. N. On-Line Time-of-Flight Mass Spectrometric Analysis of Peptides Separated by Capillary Electrophoresis. Anal. Chem. 1994, 66, 3696-3701.

11. Cao, P.; Moini, M. Analysis of Peptides, Proteins, Protein Digests, and Whole Human Blood by Capillary Electrophoresis/Electrospray Ionization-Mass Spectrometry Using an InCapillary Electrode Sheathless Interface. J. Am. Soc. Mass Spectrom. 1998, 9, 1081-1088.

12. Wahl, J. H.; Smith, R. D. Comparison of Buffer Systems and Interface Designs for Capillary Electrophoresis-Mass Spectrometry. J. Cap. Electr. 1994, 1, 62-71.

13. Figeys, D.; Ducret, A.; Yates, J. R., III; Aebersold, R. Protein Identification by Solid Phase Microextraction-Capillary Zone Electrophoresis-Microelectrospray-Tandem Mass Spectrometry. Nat. Biotech. 1996, 14, 1579-1583.

14. Severs, J. C.; Smith, R. D. Characterization of the Microdialysis Junction Interface for Capillary Electrophoresis/Microelectrospray Ionization Mass Spectrometry. Anal. Chem. 1997, 69, 2154-2158.

15. Alexander, J. N., VI; Schultz, G. A.; Poli, J. B. Development of a Nanoelectrospray Mass Spectrometry Source for Nanoscale Liquid Chromatography and Sheathless Capillary Electrophoresis. Rapid Commun. Mass Spectrom. 1998, 12, 1187-1191.

16. Emmett, M. R.; Caprioli, R. M. Micro-Electrospray Mass Spectrometry: Ultra-High-Sensitivity Analysis of Peptides and Proteins. J. Am. Soc. Mass Spectrom. 1994, 5, 605-613.

17. Licklider, L. J.; Thoreen, C. C.; Peng, J.; Gygi, S. P. Automation of Nanoscale Microcapillary Liquid Chromatography-Tandem Mass Spectrometry with a Vented Column. Anal. Chem. 2002, 74, 3076-3083.

18. Stewart, I. I.; Zhao, L.; Le Bihan, T.; Larsen, B.; Scozzaro, S.; Figeys, D.; Mao, G. D.; Ornatsky, O.; Dharsee, M.; Orsi, C.; Ewing, R.; Goh, T. The Reproducible Acquisition of Comparative Liquid Chromatography/Tandem Mass Spectrometry Data from Complex Biological Samples. Rapid Commun. Mass Spectrom. 2004, 18, 1697-1710.

19. Lopez-Herrera, J. M.; Barrero, A.; Boucard, A.; Loscertales, I. G.; Marquez, M. An Experimental Study of the Electrospraying of Water in Air at Atmospheric Pressure. J. Am. Soc. Mass Spectrom. 2004, 15, 253-259.

20. Embrechts, J.; Lemiere, F.; Van Dongen, W.; Esmans, E. L. Equilenin-2'-Deoxynucleoside Adducts: Analysis with NanoLiquid Chromatography Coupled to Nanoelectrospray Tandem Mass Spectrometry. J. Mass Spectrom. 2001, 36, 317-328. 
21. Li, W.; Hendrickson, C. L.; Emmett, M. R.; Marshall, A. G. Identification of Intact Proteins in Mixtures by Alternated Capillary Liquid Chromatography Electrospray Ionization and LC ESI Infrared Multiphoton Dissociation Fourier Transform Ion Cyclotron Resonance Mass Spectrometry. Anal. Chem. 1999, 71, 4397-4402.

22. Valaskovic, G. A.; Murphy, J. P., III; Lee, M. S. Automated Orthogonal Control System for Electrospray Ionization. J. Am. Soc. Mass Spectrom. 2004, 15, 1201-1215.

23. Huddleston, M. J.; Annan, R. S.; Bean, M. F.; Carr, S. A. Selective Detection of Phosphopeptides in Complex Mixtures by Electrospray Liquid Chromatography/Mass Spectrometry. J. Am. Soc. Mass Spectrom. 1993, 4, 710-717.

24. Sanchez-Rabaneda, R.; Jauregui, O.; Casals, I.; Andres-Lacueva, C.; Izquierdo-Pulido, M.; Lamuela-Raventos, R. M.
Liquid Chromatographic/Electrospray Ionization Tandem Mass Spectrometric Study of the Phenolic Composition of Cocoa (Theobroma cacao). J. Mass Spectrom. 2003, 38, 35-42.

25. Chatman, K.; Hollenbeck, T.; Hagey, L.; Vallee, M.; Purdy, R.; Weiss, R.; Siuzdak, G. Nanoelectrospray Mass Spectrometry and Precursor Ion Monitoring for Quantitative Steroid Analysis and Attomole Sensitivity. Anal. Chem. 1999, 71, 2358-2363.

26. Schneider, B. B.; Baranov, V. I.; Javaheri, H.; Covey, T. R. Particle Discriminator Interface for Nanoflow ESI-MS. J. Am. Soc. Mass Spectrom. 2003, 14, 1236-1246.

27. Schneider, B. B.; Guo, X.; Zhong, F.; Cox, D.; Sakuma, T.; Covey, T. R. Optimization of Nanoflow Electrospray for Negative Ion Mode and Polarity Switching. Poster presented at the 52nd Annual American Society for Mass Spectrometry Conference, 2004, Nashville, Tennessee. 